\title{
DESSALINIZAÇÃO DE ÁGUA UTILIZANDO TECNOLOGIA DE DEIONIZAÇÃO CAPACITIVA: ANÁLISE DE DIFERENTES ELETRODOS
}

\author{
R. L.ZORNITTA ${ }^{1}$ e L. A. M. RUOTOLO ${ }^{1}$ \\ ${ }^{1}$ Universidade Federal de São Carlos, Departamento de Engenharia Química \\ E-mail para contato: rafael_rlzs@hotmail.com
}

\begin{abstract}
RESUMO - A Deionização Capacitiva (DIC) é um processo de eletrossorção que se baseia na remoção de íons da solução e sua armazenagem na dupla camada elétrica. Neste trabalho foram estudados eletrodos de carvão ativado (CA) para uso em DIC. O desempenho destes eletrodos para dessalinização foi avaliado através de experimentos de remoção de cloreto de sódio em um sistema em batelada com recirculação. A caracterização morfológica foi realizada através de microscopia eletrônica de varredura. Um planejamento fatorial de experimentos foi realizado e avaliou-se as condições de preparação do eletrodo variando-se a composição de CA, PVDF (aglutinante), negro de acetileno (para melhorar a condutividade) e $\mathrm{NaCl}$ (para aumentar a porosidade do eletrodo). Os resultados indicaram que não há a necessidade de se utilizar o negro de acetileno e que a utilização do $\mathrm{NaCl}$ na preparação do eletrodo promoveu um aumento da remoção de íons em eletrodos espessos.
\end{abstract}

\section{INTRODUÇÃO}

A obtenção de água potável é um desafio que se torna cada vez mais importante na sociedade contemporânea. Da água utilizada pelo homem, estima-se que somente $8 \%$ é para consumo, 69\% é utilizada na agricultura e 23\% na indústria (Phillippi et al., 2004). Desta forma, fica evidente que o desenvolvimento econômico e social de uma região está intrinsecamente ligado à questão da água.

Conforme a Associação de Geógrafos Brasileiros, em 2004 existiam aproximadamente 3000 sistemas de dessalinização por osmose reversa instalados na região semiárida do nordeste. Porém, boa parte destes equipamentos não estava funcionando devido à falta de manutenção e ao seu mau uso. A dessalinização utilizando tecnologia de deionização capacitiva surge como uma alternativa simples e de baixo custo para a obtenção de água potável nestas regiões.

\subsection{DIC}

A tecnologia de DIC: A DIC teve seus primeiros estudos datados de meados dos anos 1960 e início de 1970. O conceito foi introduzido por Caudle et al. (1966) e Johnson et al. (1970), que desenvolveram uma base teórica e também realizaram testes com alguns materiais de eletrodo. 
Algumas características são fundamentais para escolha de um novo eletrodo para deionização capacitiva, destacando-se uma grande área superficial, grande disponibilidade de microporos para adsorção, boa condutividade elétrica e baixa resistência hidrodinâmica. Estas características são comumente encontradas em materiais de carbono, que, além disso, são altamente polarizáveis e possuem caráter anfótero, ou seja, permitem o uso de suas propriedades eletroquímicas como um elemento doador ou receptor de elétrons. Por fim, materiais de carbono podem ser considerados ambientalmente corretos (Frackowiake e Béguin, 2001). Desta forma, eletrodos de carbono são frequentemente usados em DIC. Alguns materiais estudados são: carvão ativado e tecido de carvão ativado, negro de acetileno, carbono mesoporoso comercial, aerogel de carbono, nanotubos de carbono e grafeno. Vários resultados podem ser encontrados na literatura a respeito destes materiais e suas modificações através de aditivos que são depositados sobre suas superfícies. Neste trabalho foram estudados eletrodos de carvão ativado.

O processo de DIC: A DIC é um processo de eletrossorção que ocorre quando uma diferença de potencial é aplicada através de dois eletrodos. Quando uma solução contendo íons atravessa estes eletrodos, os cátions são atraídos para o eletrodo negativo e os ânions para o eletrodo positivo. Estes íons ficam retidos na dupla camada elétrica formada no interior dos poros do material (Figura 1(a) e 1(c)).
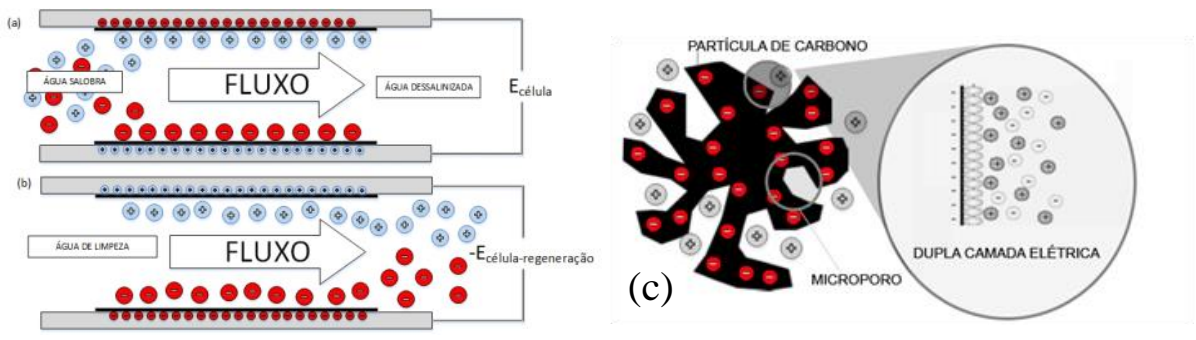

Figura 1 - (a) eletrossorção: os cátions da solução são atraídos para o eletrodo negativo e os ânions para o eletrodo positivo; (b) regeneração: o potencial é invertido e os cátions e

ânions sofrem repulsão e são liberados novamente para a solução; (c) representação esquemática de uma partícula em um eletrodo de carbono carregado negativamente e dos cátions retidos na dupla camada elétrica.

Após a saturação do eletrodo ou após a cinética de eletrossorção se tornar muito lenta procede-se então ao processo de regeneração. Quando se deixa de aplicar o potencial de eletrossorção ou então se inverte o potencial, os íons deixam de estar sujeitos à força eletrostática que os mantinha retidos na dupla camada elétrica e são liberados novamente na solução, como observado na Figura 1(b). Quando os íons estão sendo liberados da dupla camada elétrica uma parte da energia usada na eletrossorção pode ser recuperada, de forma similar a um capacitor. Portanto, uma outra vantagem da tecnologia DIC é a possibilidade de recuperação de parte da energia utilizada na eletrossorção.

\section{MATERIAIS E MÉTODOS}

\subsection{Preparação dos eletrodos}


A preparação dos eletrodos de carvão ativado foi baseada nos resultados obtidos por Park et. al. (2007). Eles observaram que a proporção ideal para manter a estabilidade física do eletrodo e ao mesmo tempo não interferir na acessibilidade aos poros, além de melhorar a condutividade do material, é: $86 \%$ de material de carbono (pó de carvão ativado), $4 \%$ de aglomerante (fluoreto de polivinilideno (PVDF)) e $12 \%$ de negro de acetileno (NA). Neste trabalho estudou-se a influência da quantidade de negro de acetileno, mantendo-se fixa a proporção de $96 \%$ de carvão ativado e $4 \%$ de PVDF. Na preparação de alguns eletrodos adicionou-se também $\mathrm{NaCl}$ visando a obtenção de um eletrodo mais poroso após sua dissolução ao final do processo de preparação.

Os materiais de eletrodo foram pesados e misturados em um béquer, ao qual foi adicionado o solvente ciclopentanona que atua como dispersante do PVDF. Esta mistura foi então espalhada sobre um substrato de grafite que estava preso a um molde utilizado para obter o eletrodo nas dimensões desejadas. O molde foi então levado à estufa a uma temperatura de $130^{\circ} \mathrm{C}$ para evaporação do solvente (Silva, 2011). As dimensões do eletrodo eram: $10 \mathrm{~cm}$ de altura e $5 \mathrm{~cm}$ de largura. $\mathrm{O}$ diâmetro médio das partículas de $\mathrm{CA}$ era de 0,085 $\mathrm{mm}$. No caso dos eletrodos preparados com $\mathrm{NaCl}$, após serem retirados da estufa os mesmos foram mergulhados em $2 \mathrm{~L}$ de água deionizada e mantidos por 1 dia com a finalidade de dissolver todo o $\mathrm{NaCl}$ presente no eletrodo.

\subsection{Caracterização dos eletrodos}

Os eletrodos foram caracterizados através de um processo de dessalinização em batelada no qual uma solução salina na concentração de 300 ppm e 600 ppm era alimentada em uma célula de DIC em uma vazão de $22,5 \mathrm{~mL} \mathrm{~min}^{-1}$. Na saída da célula um sensor de condutividade acoplado ao computador media a condutividade da solução a cada 30 segundos.

Um potenciostato (AUTOLAB, modelo PGSTAT30) foi utilizado para fornecer a diferença de potencial à célula.

O processo de dessalinização foi avaliado em termos da porcentagem de íons removidos, \% R (Equação 01), eficiência coulômbica, EC (Equação 02) e consumo energético específico, CEE (Equação 03).

$$
\begin{aligned}
& \% R=\frac{C_{0}-C}{C_{0}} \\
& E C=100 \frac{z F V \Delta C}{\int I d t} \\
& C E E=\frac{E_{\text {cell }} \cdot \int I d t}{V}
\end{aligned}
$$

Nas Equações 1, 2 e 3, $\mathrm{C}_{0}$ é a concentração inicial da solução, C a concentração após um determinado tempo de processo, $\mathrm{z}$ é o coeficiente estequiométrico da quantidade de elétrons fornecida ao íon, $\mathrm{F}$ o número de Faraday, $\mathrm{V}$ o volume de eletrólito, $\Delta \mathrm{C}$ a variação da concentração em um intervalo de tempo t, I a corrente aplicada e $\mathrm{E}_{\text {cell }}$ é o potencial de célula. 


\subsection{Dessalinização}

Os experimentos de dessalinização foram realizados utilizando eletrodos preparados com diferentes proporções de $\mathrm{CA}+\mathrm{PVDF}, \mathrm{NA}, \mathrm{NaCl}$ e aplicando-se diferentes valores de $\mathrm{E}_{\text {cell. }}$. Para minimizar o número de experimentos e obter as informações desejadas, foi utilizado um planejamento fatorial de experimentos $2^{4}$ com 3 pontos centrais. Os níveis e os valores codificados do planejamento são mostrados na Tabela 1 .

Tabela 1 - Níveis e valores codificados das variáveis

\begin{tabular}{|c|c|c|c|}
\cline { 2 - 4 } \multicolumn{1}{c|}{} & \multicolumn{3}{c|}{ níveis } \\
\hline $\mathrm{E}_{\mathrm{cell}} / \mathrm{V}$ & -1 & 0 & +1 \\
\hline $\mathrm{CA} / \mathrm{g}$ & 1,0 & 1,2 & 1,4 \\
\hline$\% \mathrm{NaCl}$ & 0,600 & 0,825 & 1,050 \\
\hline$\% \mathrm{NA}$ & 0 & 15 & 30 \\
\hline
\end{tabular}

\section{RESULTADOS E DISCUSSÃO}

\section{1 . Planejamento fatorial}

A Figura 2(a) mostra o diagrama de Pareto com o efeito de cada variável para a resposta $\%$ R. Se torna evidente que o potencial de célula possui o maior efeito na remoção de íons da solução, seguido pela massa do eletrodo. As demais variáveis não tiveram efeito significativo, considerando um grau de significância de $90 \%$.

A Figura 2(b) mostra a superfície de contorno para a $\% \mathrm{R}$ em função de $\mathrm{E}_{\text {cell }}$ e massa de CA. Pode-se observar que maiores valores de potencial associados a maiores valores de massa de CA levam a remoções de $\mathrm{NaCl}$ superiores a 0,24 ou $24 \%$.

(a)

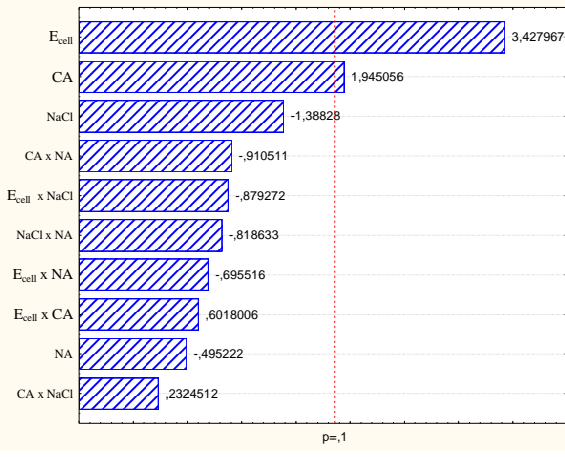

(b)

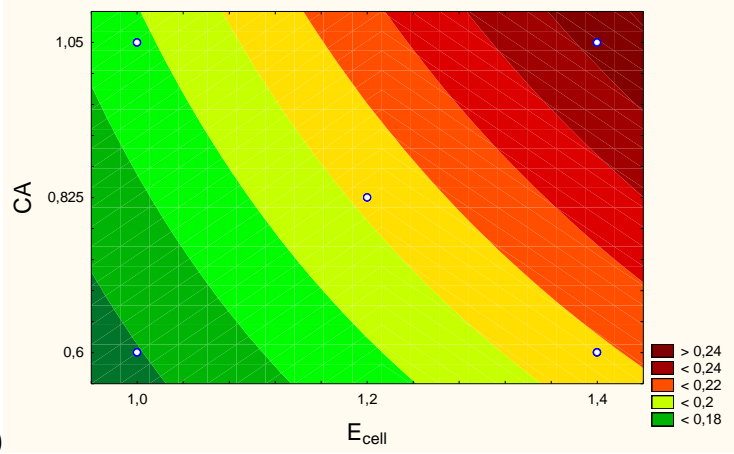

Figura 2 - (a) Diagrama de Pareto. (b) Superfície de contorno para remoção de $\mathrm{NaCl}$.

O segundo parâmetro analisado foi a EC. Neste caso, o diagrama de Pareto revela que somente o potencial de célula teve influência sobre a EC, conforme mostrado na Figura 3(a). $\mathrm{O}$ valor negativo indica que quanto maior o valor do potencial de célula utilizado, menor será a eficiência de coulômbica. 
(a)

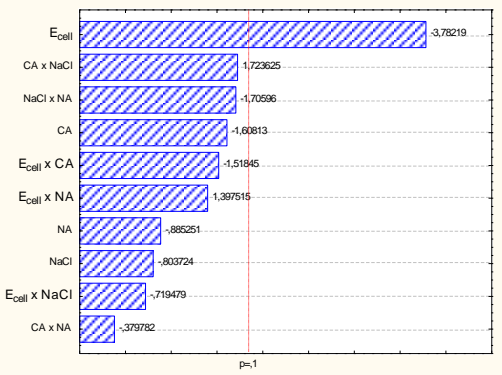

(b)

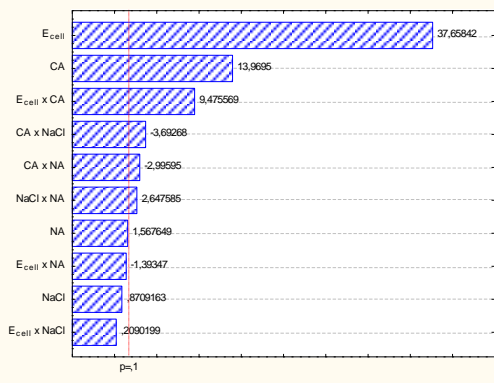

Figura 3 - Diagrama de Pareto para EC (a) e para CEE(b).

Com relação ao CEE, o diagrama de Pareto mostrado na Figura 3(b) mostra que somente os efeitos individuais das variáveis $\mathrm{E}_{\text {cell }}$ e $\mathrm{CA}$ tiveram efeito significativo, enquanto os efeitos de $\mathrm{NA}$ e $\mathrm{NaCl}$ aparecem somente em termos de interação. De qualquer forma, as variáveis que apresentam os maiores efeitos significativos sobre o CEE continua sendo $\mathrm{E}_{\text {cell }}$ e CA, conforme observado também para a $\% \mathrm{R}$. $\mathrm{O} \mathrm{E}_{\text {cell }}$ tem um grande efeito positivo sobre processo de eletrossorção, ou seja, um aumento do potencial de célula leva a um grande aumento da $\% \mathrm{R}$ e do CEE, conforme pode ser constatado nas Figuras 2(b) e 4(b), respectivamente.

A Figura 4(a) mostra que o menor CEE é obtido quando se utiliza a menor massa de CA e na ausência de $\mathrm{NaCl}$. Apesar do aumento da massa de CA levar a maiores valores de \%R, o CEE aumenta devido ao aumento da resistência do eletrodo, que possui uma espessura maior quando uma massa maior de $\mathrm{CA}$ é utilizada. $\mathrm{O}$ uso de $\mathrm{NaCl}$ na preparação do eletrodo aparentemente não levou a uma melhoria do processo de eletrossorção através do que seria uma melhoria da molhabilidade do eletrodo. No entanto, seu efeito aparece em termos de interação principalmente com a variável CA.

É interessante notar que em todos os casos, tanto para \%R e EC quanto para CEE, se verificou que o percentual de NA não foi significante, ou seja, indicando que sua utilização na preparação do eletrodo não é necessária, ao contrário do que sugere a literatura (Park et al., 2007).

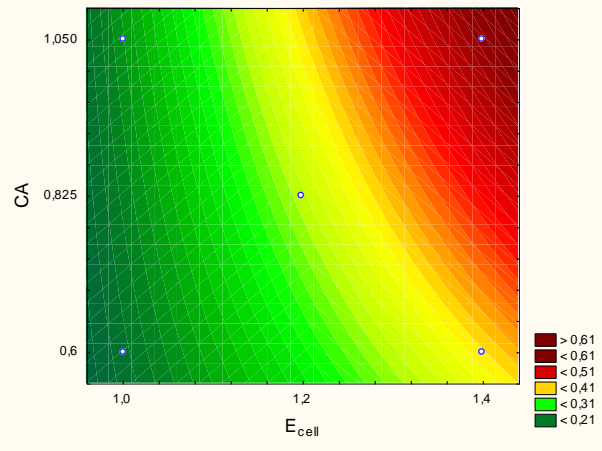

(a)

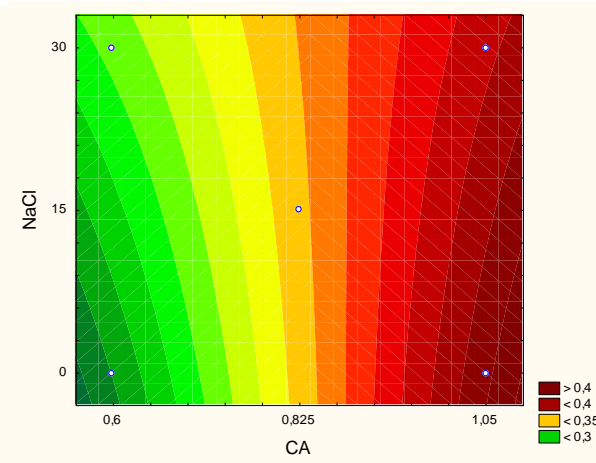

(b)

Figura 4 - (a) Superfície de contorno do consumo energético específico para variação da $\% \mathrm{NaCl}$ e da massa de CA. (b) Superfície de contorno para o consumo energético específico para a variação da massa de CA e o do $\mathrm{E}_{\text {cell }}$. 


\subsection{Efeito da adição de $\mathrm{NaCl}$ na preparação do eletrodo}

Quatro pares de eletrodos foram preparados e utilizados em um processo de dessalinização para estudar especificamente o efeito da adição de $\mathrm{NaCl}$ no procedimento de preparação do eletrodo. Os eletrodos possuem as composições mostradas na Tabela 2.

Tabela 2 - Composição de preparação dos eletrodos de CA e NaCl

\begin{tabular}{|c|c|c|}
\hline Eletrodo & Massa de CA / $~$ & $\% \mathrm{NaCl}$ \\
\hline $1(\mathrm{CAF})$ & 0,600 & 0 \\
\hline $2(\mathrm{CAS30F})$ & 0,600 & 30 \\
\hline $3(\mathrm{CAE})$ & 1,050 & 0 \\
\hline $4(\mathrm{CAS} 30 \mathrm{E})$ & 1,050 & 30 \\
\hline
\end{tabular}

$\mathrm{O}$ processo de dessalinização foi realizado com o potencial de célula de $1,2 \mathrm{~V}$ e uma solução salina de 600 ppm. A Figura 5(a) mostra uma comparação da \%R em função do tempo entre os 4 eletrodos. Pode-se observar que a maior remoção foi atingida pelo eletrodo 4 , chegando a mais de $26 \%$, porém, o eletrodo 3 foi o que apresentou maior cinética de remoção. A maior remoção obtida utilizando o eletrodo 4 deveu-se provavelmente ao maior acesso dos íons proporcionado pelos poros gerados pela dissolução do $\mathrm{NaCl}$, os quais estavam indisponíveis no eletrodo 3. Já a menor cinética de remoção do eletrodo 4 em relação ao eletrodo 3 poderia ser explicada pela morfologia do eletrodo.

Realizou-se também uma análise para verificar se ocorreu alguma diferença na cinética de dessorção dos íons que estavam eletrossorvidos no eletrodo. O que se observa na Figura 5(b) foi que a utilização do $\mathrm{NaCl}$ na preparação do eletrodo não alterou a cinética de dessorção.

Na Figura 5(c) pode-se observar a remoção específica calculada após a saturação do eletrodo. Nota-se que a utilização ou não de $\mathrm{NaCl}$ não fez diferença para os eletrodos finos. Analisando somente os eletrodos espessos, a utilização do $\mathrm{NaCl}$ proporcionou uma maior remoção, mesmo assim o maior acesso dos íons ao interior dos poros do eletrodo que teria sido criado pelo $\mathrm{NaCl}$ não foi o suficiente para permitir que a remoção do eletrodo 4 fosse igual aos dos eletrodos finos 1 e 2 .

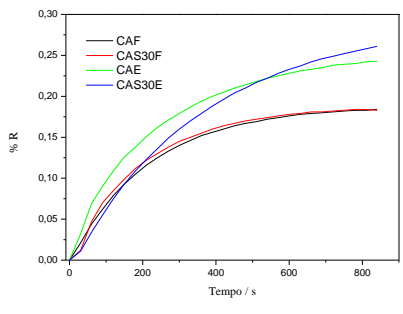

(a)

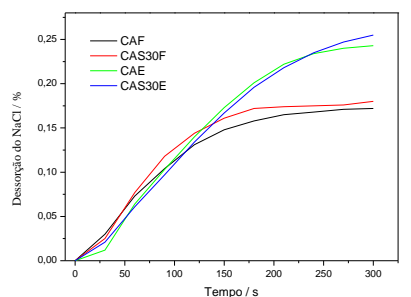

(b)

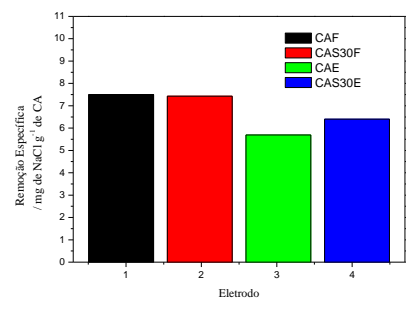

(c)

Figura 5 - (a) \% R de $\mathrm{NaCl}$ em função do tempo; (b) dessorção do $\mathrm{NaCl}$; (c) Remoção específica de $\mathrm{NaCl}$ obtida após a total saturação do eletrodo.

O CCE e a EC para os quatro eletrodos são mostrados nas Figuras 6(a) e 6(b), respectivamente. Como se pode observar, o CEE e o EC permaneceram praticamente constantes para todos os eletrodos. 


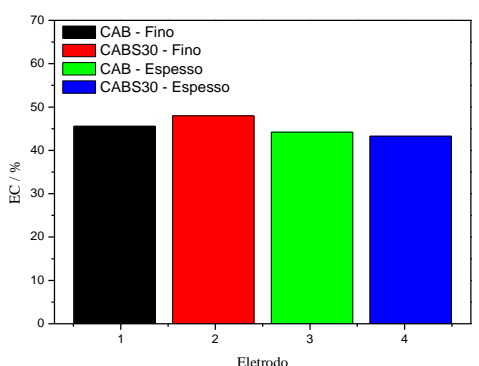

(a)

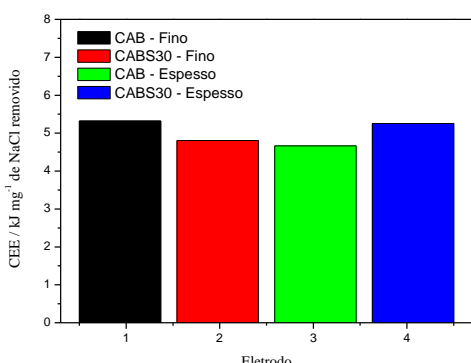

(b)

Figura 6 -EC (a) e CEE (b) para os eletrodos estudados.

A Figura 7 mostra as imagens $\mathrm{MEV}$ de 2 eletrodos preparados com $\mathrm{NaCl}$, sendo a Figura 7(a) para o eletrodo mais fino e a 7(b) para o eletrodo espesso.

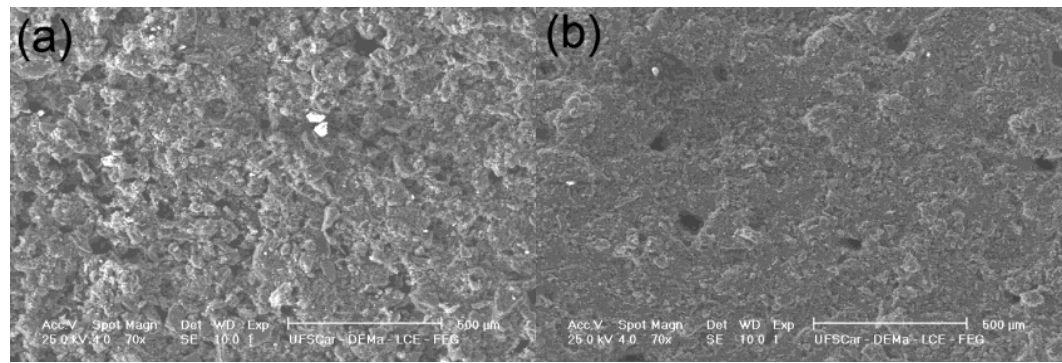

Figura 7 - Imagens MEV do eletrodo CAS30F (a) e CAS30E (b).

Nota-se que para o eletrodo mais fino (Figura 7(a) a estrutura é mais aberta e com mais poros, enquanto na Figura 7(b) podem ser vistos alguns orifícios na superfície, que é mais compacta e homogênea. Estes orifícios seriam originados pela dissolução das partículas do $\mathrm{NaCl}$ adicionado no processo de preparação do eletrodo. Como resultado, a parte interna do eletrodo provavelmente teve uma maior quantidade de caminhos para a solução salina entrar em contato com o CA, aumentando, assim, a quantidade total de remoção destes íons. Por outro lado, a superfície mais densa impede que este processo seja rápido devido à existência dos caminhos preferenciais, piorando sua cinética de eletrossorção.

\section{CONCLUSÃO}

As principais conclusões do trabalho foram:

$\checkmark$ A adição do negro de acetileno não apresentou efeito significativo no eletrodo de CA para remoção de $\mathrm{NaCl}$, EC e CEE;

$\checkmark$ O potencial de célula foi a variável que mais influenciou as variáveis resposta estudadas, seguida pela massa de CA;

$\checkmark$ A adição de $\mathrm{NaCl}$ ao eletrodo de maior espessura proporcionou um aumento na remoção de $\mathrm{NaCl}$ ao mesmo tempo que apresentou uma redução na cinética de remoção; 
$\checkmark$ A adição de $\mathrm{NaCl}$ ao eletrodo fino não demonstrou alteração em nenhum dos parâmetros analisados;

$\checkmark$ Os valores de remoção específica dos eletrodos finos com e sem $\mathrm{NaCl}$ foram superiores aos dos eletrodos espessos;

$\checkmark$ Para os eletrodos de $\mathrm{CA}+\mathrm{NaCl}$ observou-se que os valores do $\mathrm{CEE}$ e da EC permaneceram praticamente constantes, diferente dos eletrodos que continham NA na sua composição.

\section{AGRADECIMENTOS}

Os autores agradecem à FAPESP e ao CNPQ pelo apoio financeiro.

\section{REFERÊNCIAS}

CAUDLE, D. D.; TUCKER, J.H.; COOPER, J.L.; ARNOLD, B.B.; PAPASTAMATAKI, A. Eletrochemical Demineralization of Water with Carbon Electrodes, Research Report, Oklahoma University Research Institute, May 1966, 205 p.

FRACKOWIAK, E.; BÉGUIN, F. Carbon materials for the electrochemical storage of energy in capacitors, Carbon 39 (2001) 937-950.

JOHNSON, A.M.; VENOLIA, A.W.; NEWMAN, J.; WILBOURNE, R.G.; WONG, C.M.; GILLAM, W.S.; JOHNSON, S.; HOROWITZ, R.H. Electrosorb Process for Desalting Water, Office of Saline Water Research and Development Progress Report No. 516, U.S. Dept. Interior Pub. 200 056, March 1970, 31 p.

PARK, K.; LEE, J.; PARK P.; YOON S.; MOON, J.; EUM, H.; LEE, C. Development of a carbon sheet electrode for electrosorption desalination. Desalination 206 (2007) 86-91.

PHILIPPI, A. J.; ROMERO M. A.; COLLET B. G. Curso de Gestão Ambiental. Editora Manole, Barueri-SP, 2004. 1045p.

SILVA, J. P.; Síntese assistida por microondas de LiMn2O4, caracterização e testes como catodo para dispositivos de armazenamento de energia, Dissertação de mestrado, UFSCar, 2011. 